Article - 75 years - Special Edition

\title{
Projects for Predictive Maintenance and Operation between COPET G\&T and Gnarus Institute
}

\section{Clailton Leopoldo da Silva ${ }^{1}$}

https://orcid.org/0000-0001-7840-0352

Rafael Martins ${ }^{1}$

https://orcid.org/0000-0002-0776-2978

\section{Carlos Eduardo Xavier ${ }^{1}$}

https://orcid.org/0000-0002-1144-7276

Júlio Cezar Oliveira Castioni ${ }^{1}$

https://orcid.org/0000-0002-1144-9247

\author{
João Felipe Barbosa ${ }^{2}$ \\ https://orcid.org/0000-0003-4779-7304
}

Tiago Gonçalves Zacarias ${ }^{2}$

https://orcid.org/0000-0002-0156-6546

\section{Diogo Gonzaga Marcelo²}

https://orcid.org/0000-0002-5832-9402

Frederico de Oliveira Assunção ${ }^{2}$

https://orcid.org/0000-0002-5304-8628

\section{Germano Lambert-Torres ${ }^{2 *}$}

https://orcid.org/0000-0003-3789-4696

${ }^{1}$ COPEL Generation and Transmission, Curitiba, PR, Brazil; ${ }^{2}$ Gnarus Institute, Itajuba, Minas Gerais, Brazil.

Editor-in-Chief: Alexandre Rasi Aoki

Associate Editor: Alexandre Rasi Aoki

Received: 2021.03.09; Accepted: 2021.03.16.

*Correspondence: germanoltorres@gmail.com; Tel.: +55-35- 3622-0132 (G.L.T.).

\section{HIGHLIGHTS}

- Monitoring system with analysis through intelligent system techniques.

- Predictive assessment of the operating conditions of circuit breakers.

- Monitoring of lightning arresters in the face of atmospheric discharges.

- Process of detection and localization of internal faults in SF6 substations.

Abstract: The continuity of an electrical system's services is linked to its equipment's correct operation. The more correctly they worked, the higher the quality of the services provided. Thus, they must have their functioning scanned closely and that minor defects have their evolution monitored. This fact creates the possibility of making predictions about how long equipment can operate without compromising the system's continuity. This follow-up is proper for predictive maintenance. This paper presents three on-going COPEL Generation and Transmission projects in essential elements of its electrical system: circuit breakers, lightning arresters, and SF6 substation. The central idea of all monitoring projects is to check the early problem in this equipment and facilities.

Keywords: monitoring; predictive maintenance; circuit breakers; lightning arresters; SF6 substation. 


\section{INTRODUCTION}

The electricity demand is increasing, and this increased consumption is due mainly to the general improvements in the Brazilian people's living conditions. Due to this consumption trend, electrical machines started to operate in more hard regimes, often overloading or unfavorable to equipment. These operating conditions associated with the greater need for the system's reliability caused new equipment and installation monitoring techniques to be studied and developed.

This paper aims to present three on-going projects between COPEL Generation and Transmission and the Gnarus Institute. These projects have similar structures. A systematic analysis methodology will be developed and applied in a prototype for predictive evaluation of operational conditions of circuit breakers, lightning arresters, and SF6 substations, based on the information provided during the operation, associated with an intelligent mining of historical data and an intelligent system of information analysis.

The operation of circuit breakers in an electrical system subjects this equipment to stresses, which over time can cause a reduction in their operational capacity, resulting in uncertainties as to their actual situation. Thus, there is a need for a rigorous evaluation of this capacity reduction, aiming to increase the electrical system's reliability and decrease maintenance costs by the treatment more appropriate to these equipment's actual operating situation. Due to the complexity of the problem and the potential damage caused by circuit breaker failures, it is necessary to use more scientifically based methods to analyze this equipment's health and assess the possible loss of its capacity to act over a period. Thus, to solve this problem, not yet solved, this project proposes an innovative solution based on the experience of the technical team in developments, with a recognized reputation in the electrical and computational sectors. The methodology evaluates the circuit breakers' operational capacity according to the parameters obtained directly from the maneuvers and the information extracted from their history. It has its theoretical bases positioned in two methodological aspects to support the systematization process of the solution. Although each of them is associated with several other technologies that will produce the expected result, they can be divided into two large groups. The first group concerns the development of a measurement component of the operational parameters characteristic, in real-time, of the process of opening and closing the poles of the circuit breakers under test. The second relates to a method of analysis and extraction of information from databases representative of the circuit breakers' operation history under test.

The project of monitoring the operating conditions of a circuit breaker aims to make a predictive assessment of circuit breakers' operational requirements, based on the information provided during the operation of opening and closing of its poles, associated with intelligent mining of the historical data. Another objective of this methodology is to create models capable of evaluating the various aspects related to the maintenance of circuit breakers. It is intended to be able to answer questions regarding the conformity of the event history in the circuit breakers with the values specified by the manufacturers, the estimation of the cost of maintenance depending on the operating conditions, the influence of factors such as the topology of the network on the performance of the equipment, among others. The methodology developed will be supported by a project that will prepare a Data Analytics program for circuit breaker maintenance. The developed system will be laboratory tested and installed in a COPEL substation.

On the other hand, insulation failures originate from changes in metal oxide inserts' physical/chemical properties due to some stress. This stress can be of thermal, electrical, mechanical, or chemical origin. When this stress is large enough, the mechanisms of failure at the weakest points are formed. If this stress persists, isolation weakens, and a rupture can occur at the weak points. This fact is the typical mechanism of faults in isolation, and the lightning arresters are no different.

The lightning arrester monitoring project aims to monitor the wear and tear of these equipment scans in the face of the passage of atmospheric discharges. A system (hardware and software) will be developed for the on-line monitoring of the conditions of this equipment's inserts through the impedance spectrum technique. Signals from various frequencies will be injected harmlessly into the lightning arresters to collect their response in frequency. Then, the signal processing algorithms will collect these responses and establish the degree of wear of the inserts of this equipment, which, in the end, represent their effectiveness in containing the atmospheric discharges that arrive via the transmission lines in the substation. The signals will be injected into the lightning arresters through a signal-generating device to be built for this purpose. The developed system (hardware and software) will be tested in the laboratory with station-type lightning arresters with metal oxide resistors to establish a wear chart, which is a table that tries to relate the events that occurred in the electrical system with the burns that appear on the inserts. The developed system will be installed on COPEL lightning arresters. 
Gas-insulated substations are less subject to shutdowns in their normal operating phase (i.e., after commissioning tests and in-operation in-system) than conventional air substations. This fact can be easily proven with the failure rates presented by these two facilities over the years. However, it is also confirmed that the duration of the failures (i.e., the time of correction of the defect and the return to regular operation) is much higher in the gas-insulated substations. It occurs because the process of locating the fault tends to be time-consuming, as well as its repair that depends on the removal and subsequent replacement of the gas, restoration of the defect, and the procedures for checking the tightness of the compartment.

The design of SF6 gas-insulated substations aims to detect and locate internal faults in their compartments and monitor the transmission lines connected to the substation. Via a set of sensors and signal processing algorithms, it is possible to determine where the short circuit occurred and monitor the transmission lines' operation. The sensor set used will consist of some of the same and others of the existing measurement system. All data are collected on-line and ultimately non-invasive. It does not affect the substation's functioning in any form or impair its warranty. Signal processing algorithms will be made based on intelligent hybrid techniques, mixing deep convolutional plastic neural network techniques, higher-order statistical processing, and case-based reasoning techniques. The developed system (hardware and software) will be tested in the laboratory and installed in a COPEL Curitiba substation.

\section{Circuit breaker monitoring project}

The primary motivation of this project is linked to the importance of circuit breakers in electrical networks. This equipment, responsible for opening the circuits both in maneuvers and short-circuits, must always be prepared to act mainly in the second case, in the presence of faults; its correct performance depends on the complete operational security of the system. However, the circuit breakers and other equipment of the electrical system suffer strain throughout its service life. These wears affect both their electrical parts, the insulations, and their mechanical part, such as the poles' opening drive coils. With this, in the face of these wears and tears, its disruptive capacity can be changed over time. Thus a circuit breaker that at the beginning of its service life was specified to open a certain short circuit current may have its opening capacity reduced, for example, by the fall of the quality of insulation, which in the case of this project is SF6 gas.

This reduction in stopping capacity is that several factors can occur, even though it is expected to occur over its lifetime. A leak of SF6 gas, a softening of springs and the mechanical system of opening the poles, over temperatures in the equipment, and wear on the head of the poles' contacts are factors that can generate problems in the correct performance of the circuit breakers.

Thus, this project's central idea is to develop a system that can continuously and on-line check the degree of wear of SF6 circuit breakers. This system will have sensors installed non-invasively to capture the currents' signals that pass through the circuit breaker. With historical, constructive, and operational data, this information will be conveniently manipulated with modern knowledge extraction techniques. This fact allows the evolution of the various observed signals, enabling the maintenance team to observe the circuit breaker's operational conditions and the degradation of its interruption capacity. It is also possible to mitigate possible electrical system problems due to the circuit breaker's poor performance. Figure 1 shows the pictorial form of this solution.

\section{Main Objectives of this Project}

The research project's main objective is to develop and prove a methodology and subsequent preparation of a demonstrative prototype for the on-line monitoring of the circuit breakers' operational condition, with the early identification of problems that may affect their interrupting capacity.

In general, the reduction of the circuit breakers' interruption capacity is linked to mechanical and-or electrical wear, which may have several reasons, from misfits (or clearances) in their mechanical structure to loss of insulating material (in this case, leakage of SF6 gas). The more these problems are accentuated, the greater the wear and tear operation of the circuit breakers and the greater the done in their ability to interrupt short-circuit currents.

\section{State of the Art}

The operation of circuit breakers in an electrical system subjects this equipment to stresses, which over time can cause a reduction in their operational capacity, resulting in uncertainties as to their actual situation. There is a need for a rigorous evaluation of this capacity reduction, aiming to increase the electrical system's 
reliability and decrease maintenance costs by the treatment more appropriate to this equipment's actual operating situation.

Due to the complexity of the problem and the potential damage caused by circuit breaker failures, it is necessary to use more scientifically based methods to analyze this equipment's health and assess the possible loss of its capacity to act over a period. As this problem is not yet solved, this project proposes an innovative solution based on the technical team's experience in developments, with a recognized reputation in the electrical and computational sectors.

The methodology has its theoretical bases positioned in two methodological aspects to support the solution's systematization process. Although each of them is associated with several other technologies that will produce the expected result, they can be divided into two large groups. The first methodological aspect concerns developing a measurement component of the operational parameters characteristic, in real-time, opening and closing the circuit breakers' poles under test. The second relates to a process of analysis and extraction of information from databases representative of the circuit breakers' operation history under test.

Initial work on the deterioration of circuit breakers, still oil, began in the 1940s with Fordham Cooper [1] and Balsbaugh and Assaf [2]. In these works, they already drew attention to the insulator's degradation over the circuit breaker's life and already indicated the decline of its disruptive capacity. However, the essential papers began to be published in the 1980s. Leclerc, Smith, and Jones [3], on gas pressure transients in the circuit breakers. And Sim and Endrenyi [4], on equipment failures [including circuit breakers] due to the deterioration of their isolation, including a methodology based on Poisson curves, were presented in this work. In 1989, a very interesting paper was published by Toshiba engineers in Japan [5] on the results of some tests a substation to SF6 of $300 \mathrm{kV}$, decreased size, and the implications on insulation including in the circuit breaker.

In the 2000s, a group of engineers from Cutler-Hammer Predictive Diagnostics published an article [6] on partial discharges in medium voltage installations, bringing exciting ideas about sensors and processing of acquired signals. In 2002, engineers from Chubu Electric Power Co. in Japan published a study [7] on the deterioration of the isolation of a $77 \mathrm{kV} \mathrm{SF} 6$ substation with 30 years of operation, showing the main points of this degradation. In 2003, another group of engineers from Chubu Electric Power Co. published an article [8] with an accelerated aging test of the isolation of an SF6 substation of $84 \mathrm{kV}$, performing subsequent measurements with various equipment types to verify the main points of degradation of the insulation.

Two other interesting articles for our project were published in the mid-2000s, one by a group of American professors, on probabilistic models for the inspection and maintenance of circuit breakers [9] and the other by Japanese engineers on a chemical assessment of the deterioration of circuit breaker insulation [10]. In 2008, this same group of engineers from Mitsubishi Electric Co. published another article [11] on circuit breakers' chemical monitoring. In 2009, Chubu engineers republished a paper [12] on criteria for evaluating circuit breakers' deterioration to replace them.

In 2012, a group of Chinese researchers presented a study [13] on gas pressure in SF6 installations, including circuit breakers, with the proposition of sensors for data collection. In 2013, Thai researchers presented a study [14] on performance evaluation and obsolescence of $115 \mathrm{kV}$ circuit breakers. In 2013, Guan and coauthors [15] published an article on evaluating circuit breakers' life based on their operative data. In 2016, Chinese researchers published a paper [16] on the influence of metallic debris on the isolation of SF6 facilities, showing examples in a $126 \mathrm{kV}$. Finally, in 2018, two other works continue to be published in this project, showing their relevance worldwide. The first [17] reports a new procedure for detecting problems in the contacts of circuit breakers. In contrast, the second [18] proposes an assessment of circuit breakers' life cycle based on data acquired on-line.

\section{Lightning arrester monitoring project}

The motivation of this research project is linked to the importance of lightning arresters in high voltage installations. Its correct performance in these facilities is of fundamental importance both for electrical systems' operation and to avoid wearing or burning the substation's other equipment. However, the monitoring of wear and operating conditions of the lightning arrester itself is not the target of specific monitoring.

There is still the discharge counter in the older lightning arresters, which counts the number of performances (atmospheric discharges that pass through the lightning arrester). Yet, this single parameter is not entirely reliable because the important thing is not only the number of atmospheric discharges that pass through the equipment but the energy that passes through it. That is, the intensity of the electric current that reaches the substation and that it prevents it from getting the other equipment of the substation. This fact is 
because the atmospheric discharge current degrades the tablets that make up the lightning arresters. In this way, a single high-intensity atmospheric discharge can be much more malefic to the lightning arrester than several low-intensity. Thus, the discharge counter on the lightning arrester can even give an erroneous indication of its current state.

Thus, Copel chose, in its new ventures, not to have installed the discharge counter anymore because the number of performances is no longer used as a parameter for replacing the lightning arresters, opting for preventive maintenance.

This project's central idea is to develop a continuous and on-line device to check the degree of wear of the lightning arrester. This device will be installed at the entrance and exit of the equipment. The part installed at the input (i.e., at high voltage) will be self-powered with the electrical system's energy. It will inject signals at various frequencies through a current transducer, affecting the other system's other equipment. In part installed at the exit of the lightning arrester (i.e., at ground level), the signal will be captured, and the primary processing and indications will occur. They are leading COPEL to move from preventive maintenance to a predictive maintenance process.

\section{Main Objectives of this Project}

This research project's main objective is to develop and prove a methodology and subsequent preparation of a demonstrative prototype for the on-line monitoring of the operating conditions of lightning arresters, with the early identification of damage to their internal inserts.

In general, the degradation of the ray pads originates from changes in the physical/chemical properties of the metal oxide tablets due to some type of electrical stress. When this stress is large enough, the mechanisms of failure at the weakest points are formed. If this stress persists, isolation weakens, and a rupture can occur at these weak points.

\section{State of the Art}

In general, insulation failures originate from changes in metal oxide inserts' physical/chemical properties due to some type of stress. This stress can be of thermal, electrical, mechanical, or chemical origin. When this stress is large enough, the mechanisms of failure at the weakest points are formed. If this stress persists, isolation weakens, and a rupture can occur at the weak points. This fact is the typical mechanism of faults in isolation and the arresters are no different.

Thus, two revisions should be made of state of art in this section. The first revision is linked to the literature on the same effect of atmospheric discharges on the tablets of the lightning arrests. The second revision is related to the chosen technique used to verify the inserts' status, i.e., the impedance spectroscopy technique.

Grzybowski and Gao [019], in 1999, verified the effects caused by outbreaks of atmospheric discharges and overvoltages of switchings in lightning arresters after 25 years of operation. In 1999, Garcia-Gracia and coauthors [20] studied the absorption of energy by the lightning arresters using the transient electromagnetic program (EMTP) to improve the equipment's spark elements' design. In 2000, Martinez and Zanetta [21] discussed the determination of the ability to withstand discharges of oxide-metal resistors and how to model the probability of failure of a lightning arrester. In 2002, another work of the Garcia-Garcia team, published by Montanes and coauthors [22], shows that the risk of lightning faults is linked with certain aspects such as the point at which the discharge occurred, the form of the discharge, the type of spark and the configuration of the system itself.

In 2003, Lambert and coauthors [23] presented a method to predict the rate of lightning failure with a systemic application. In 2008, Christodoulou and coauthors [24] published an interesting article on lightning arrester modeling and the characteristics of their flaws. Also 2008, Xingang and coauthors [25] published the test results on various types of lightning arresters due to different parameters such as aging and humidity.

In 2011, Caulker and coauthors [26] published an article on the behavior of lightning arresters in the face of atmospheric discharges. In 2014, Jiang and coauthors [27] published a paper on the impact of various atmospheric discharges on the same lightning arrester. The effects of these multiple impacts were modeled and reproduced in the laboratory. In 2016, Bassi and Tatizawa [28] published important work on the degradation of lightning pads and their effects on their functioning. Finally, in 2017, He and coauthors [29] extended the work of multiple atmospheric discharges on the same lightning arrester, presenting unknown consequences and effects. 


\section{SF6 Gas insulated substation monitoring project}

This research project's motivation is linked to the importance of a substation representing electrical systems' operation and the continuity of their services. Notified, as SF6-armored substations near large consumer centers require high levels of continuity in their services, they are located in strategic urban points to supply energy.

Thus, when a defect comes in a substation, it usually causes shutdowns that must be located and isolated in the shortest possible time so that the substation with a new configuration can re-operate by restoring the most significant possible part (if not all) the energy that it should provide the system loads.

One of the main points that lead to the delay of this re-establishment is the time required to locate the defect points (or faults). This fault identification procedure is an essential step in the process of non-assistant of substations.

Some defects can occur in a substation whose natures are easy to interpret, enabling its rapid location. Examples of this are flashover occurrence in chains of insulators or even failures in equipment in which the protection acts correctly, signaling the circuit (or equipment) defective, the area of the event, or even the fault's location. This fact occurs when there is an internal fault in the transformer with the differential protection's correct action. In this case, it is known in which equipment the fault occurred and that it should be removed in the substation's reinstatement. However, the big problem occurs when the protection devices in the substation act outside the expected standards.

In the substations in the commissioning phase or even those already in operation, but of more complex constructive and operational natures, incorrect actions or refusals to act can reach high rates. In these substations, the location of defects with the protection sensors' improper actions usually takes a long time due to the need to analyze large amounts of information. This fact is because, in these cases, the fault can be removed by secondary protections, increasing the extent of the removed area and making it difficult to locate the faulty circuit (or equipment). Among this set of data to be analyzed, we can mention the system configuration, the type, and adjustment of the protections, event recorders, oscillograms, among other data. In the unassisted substations, it should also be considered that there is a need for a visual inspection in the courtyard of the substation, which even long, in the case of large substations, can help in this defect location.

However, this last aspect does not exist in the insulated substations of SF6, which considerably increases the difficulty in performing a response on location in this substation type. What's more, the incorrect location of a defect in this substation type is associated with a large workload of various kinds of professionals. As the circuits are packed in a compartment sealed with SF6., when defining the compartment that should be worked, some procedures must be performed, such as removal of SF6 gas, the opening of the compartment, possible repair of the defect, closing of the compartment, replacement of SF6 gas and water tightness tests of the compartment. It should be remembered that these procedures are not fast and that water tightness tests may take longer than repairing the defect itself.

Now one can imagine the inconvenience (in terms of time and costs) that a wrong location of the defective compartment may create because all the steps of the above procedure must be performed for the opening and closing of the compartment. They were taking a considerable time for its realization and without an effective solution to the problem.

\section{Main Objectives of this Project}

The main objective of this research project is the development of a methodology and subsequent preparation in the operation of a system to assist the location of faults in substations insulated to SF6 in realtime, taking into account the actions of the protections, the position of the keys, the flow of the lines and the pre-lack conditions of the substation.

This methodology will be based on pattern recognition techniques, using deep convolutional plastic neural networks with adaptive characteristics. Cases of simple faults will be selected and stored in casebased reasoning, which establishes some premises and conclusions based on certain distance types. The objective of this part of the project is through training with simple failures and correct performance. It can be inferred the proper location of a defect, even in multiple failures and actions of secondary protections.

\section{State of the Art}

Insulated substations are less subject to shutdowns in their normal operating phase (i.e., after commissioning tests and in-operation in-system) than conventional air substations. This can be easily proven with the failure rates presented by these two facilities over the years. However, it is also confirmed that the 
duration of the failures (i.e., the time of correction of the defect and the return to regular operation) is much higher in the insulated substations, mainly because the process of locating the fault tends to be timeconsuming, as well as its repair that depends on the removal and subsequent replacement of the gas, restoration of the defect and the procedures for checking the tightness of the compartment. It is not uncommon that, due to the lack of observability of the various compartments, a wrong compartment is opened, which does not present the defect, generating costs and time in addition to the process of normalization of the operation.

The location of defects in insulated substations is a research theme that even old is still open today and new significant contributions emerge. In a simple search in IEEE Xplorer arises more than 400 articles intended for this purpose.

The most interesting articles began to appear in the late 1970s and early 1980s, with the work of Mitsubishi Electric Corporation [30], Perry [31], and Chu and Tahiliani [32]. In 1982, two works deserved to be highlighted, which are: one by the duo Chu and Williamson [33], on thermal sensors, and another by Boggs [34], based on electromagnetic techniques.

In 1984, a group of engineers from The Kansai Electric Power Co, along with Sumitomo Electric Industries and Furukawa Electric Co., published practical troubleshooting results at a $275 \mathrm{kV}$ [35] SF6armored facility in Japan. Even though it is in a transmission line, this article's concepts began to be used for insulated substations.

After this contribution, only in 1989, another work worthy of mention emerged, also in a Japanese installation made by engineers from Chubu Electr. Power Co., which reported the effects of electric arcs on insulated substations [36]. In 1990, Lundgaard and coauthors [37] published a work based on the location of defects in substations protected by acoustic means. In 1990 there was also important work, even though it was not directly destined to armored substations, but showed the importance of using computers to locate faults and restoring the substation [38].

In 1993, work was created using an intelligent technique for the analysis of events in large substations. Kezunovic and his team [39] developed a specialist system to treat alarms in these substations. In 1995, Takagi and his Team at Chubu Electric Power Co [40] developed a process of locating faults in armored substations that considered the gas pressure in each of the observed compartments.

In 1996, there was an application of our research group at the Itaipu Power Plant, which gave rise to a doctoral thesis with engineer Alfredo Insfran, guided by the coordinator of this project and professor Alex Alves da Silva and the coordinator of this project, where neural networks of associative memory are used for the location of faults in the armored substation of this plant [41].

Japanese engineers remained very active in the area. In 1999 published another paper on locating faults in armored substations using gas pressure sensors, this time in a Toshiba Corp. facility. [42]. In 1999, again, Alves da Silva and coauthors [43] published another article on the Itaipu substation and its location of faults.

The next decade, in 2001, was inaugurated by Lundgaard's work [44], which located defects in insulated substations through acoustic signature. In 2008, Okabe and coauthors [45] published an article on detecting the decomposition of SF6 gases, causing isolation problems in the armored substations.

At the beginning of this decade, Kezunovic publishes two articles $[46,47]$ with new ideas for electrical systems' operation, including substations and their problems.

\section{MATERIAL AND METHODS}

These projects can be divided into three main parts: proof of concept (POC), minimum viable product (MVP), field installation, and monitoring.

The first part, the Proof of Concept (POC - Proof of Concept), is the main phase in an Applied Research project. This part is where the new on-line methodology should be designed, developed, and tested. This test is carried out in a practical model that can prove the concept. In this way, the equipment assembled for testing in this phase of the project receives the concept prototype name and serves only to show that the methodology can be applied that way and usefully.

Then, after the concept is proven, the phase of the Minimum Viable Product (MVP), which is a product that must present specific characteristics such as (a) having sufficient size to start using, (b) demonstrating benefits of its application, and (c) providing information to guide future development.

The next phase of this project is the Field Installation and Monitoring. At this stage, the demonstration prototype will be put into operation, and some fundamental steps for the success of the project will be carried out. 
In the circuit breaker monitoring project, the following steps were developed until now. The first part of the project began with a Bibliographic Review (Stage 1) on the main recent developments in the areas of techniques of capture and processing of current signals, monitoring of equipment isolated to SF6, and other types of gases and methods of extraction and interpretation of knowledge (data analytics). This review had a wide dimension, not being confined only to circuit breakers, because it is essential, in this exploratory stage, that techniques from other areas and applications be verified for possible uses in the project. In parallel to this stage, field visits will be made for data collection for the next step's definitions, the Breaker And Project Structure Study (Step 2). In this stage was defined the circuit breaker in which the demo prototype will be installed, and the project was also designed in general, that is, where the sensors will be installed and the concentrator equipment, in addition to specified other characteristics of the prototype.

At this point in the project, the team split into two. The Equipment team developed Steps 4 and 6, while the Sensors and Communication and Signal Processing and Intelligent Systems teams developed Steps 3 and 5.

In Step 3, Development of The Deterioration Monitoring of Mechanical Commands, the sensors were developed to measure the current of the mechanical parts of opening and closing of the poles and the software for interpreting these currents. In Step 5, Development of Temperature Measurement and Contact Resistance, sensor developments were initiated for measurements concerning the circuit breaker poles' contacts.

In Step 4, Assembly of a Laboratory for Testing in the Monitoring System, a laboratory was developed so that one can test all the characteristics that the sensors must collect, as well as the creation of the possibility of degradation of these signals for testing of verification of the methodology and acceptance of the prototype. In Step 6, Development of the Analysis of the Opening Parameters and the Opening Current, the construction has started the sensors to collect the information of the current that passes through the circuit breaker, verifying its signals in the subtransitory, transient and permanent phases and also in the openings and closings.

In the lightning arresters monitoring project, the following steps were developed until now. Thus, in the macro part of the Proof of Concept, this project is started or with a Bibliographic Review (Step 1) on the main recent developments in impedance spectroscopy, isolation measures, devices, and techniques injection and signal capture. This review verifies in a large dimension, not being confined only to lightning arresters, because it is essential, in this exploratory stage, that techniques related to the verification of the isolation of various equipment scans and its possible use in the project are the result of the analysis. Next, the development team looks at or on the Study of Impedance Spectroscopy in The Lightning arresters (Step 2), studying how this technique can be applied, how the actuator modules and sensor modules will be, as will be the transducers of both energy capture, injection and signal capture at the various frequencies.

In the SF6 substation monitoring project, the following steps were developed until now. This first part of the project begins or with a Bibliographic Review (Stage 1) on the main recent developments in the areas of defect tracking techniques in electrical power systems, not restricted only to armored substations, so that one can have a broader view of the frontier of scientific development in this area. Also, the techniques of neural networks were the object of this review. In parallel to this stage, field visits were made for data collection for the next step's definitions: the Study of SE SF6 and the Project Structure (Step 2). In this step, it was defined in which substation the demo prototype will be installed, and the project is also being designed in general, that is, at which points there are accesses for the installation of sensors and the concentrator equipment, in addition to specified other characteristics of the prototype. The study of the observability of substation (Step 3) occurred, analyzing the substation's measurement systems and available data in the electrical system.

\section{RESULTS}

This section shows the results obtained until now in each project.

\section{Circuit Breaker Testing Laboratory}

For the assembly of the Circuit Breaker Testing Laboratory, a tripolar circuit breaker was acquired to SF6, model GL312, with a nominal voltage of $145 \mathrm{kV}$, with a rated current of $1250 \mathrm{~A}$ and missing opening of 40KA, having manual front control, having been manufactured by ALSTOM - GE GRID SOLUTION, in 2002. This circuit breaker is of a voltage class below the GLX314X circuit breaker in which the field monitoring system will be installed but with the same mechanical drive system. 
This circuit breaker, which is the basis of the built laboratory, has the quantities of its control panel monitored by the Predictor data acquisition system acquired in this project. For this, the amounts were studied. The need was verified for installing voltage and current transducers for monitoring the contacts and solenoids of the opening and closing coils and the end-of-stroke contacts of the springs.

The frame's operation mechanism was positioned on an appropriate surface in front of the base structure. The two side panels and the operating mechanism roof were removed, using the standards specified in the circuit breaker manual. Thus, the mechanism was simply hidden by the spring protection plate, which was removed.

Figures 1 show details of the laboratory's construction, while Figure 2 shows the laboratory ready for operation. The first results are already being produced in the Circuit Breaker Testing Laboratory.

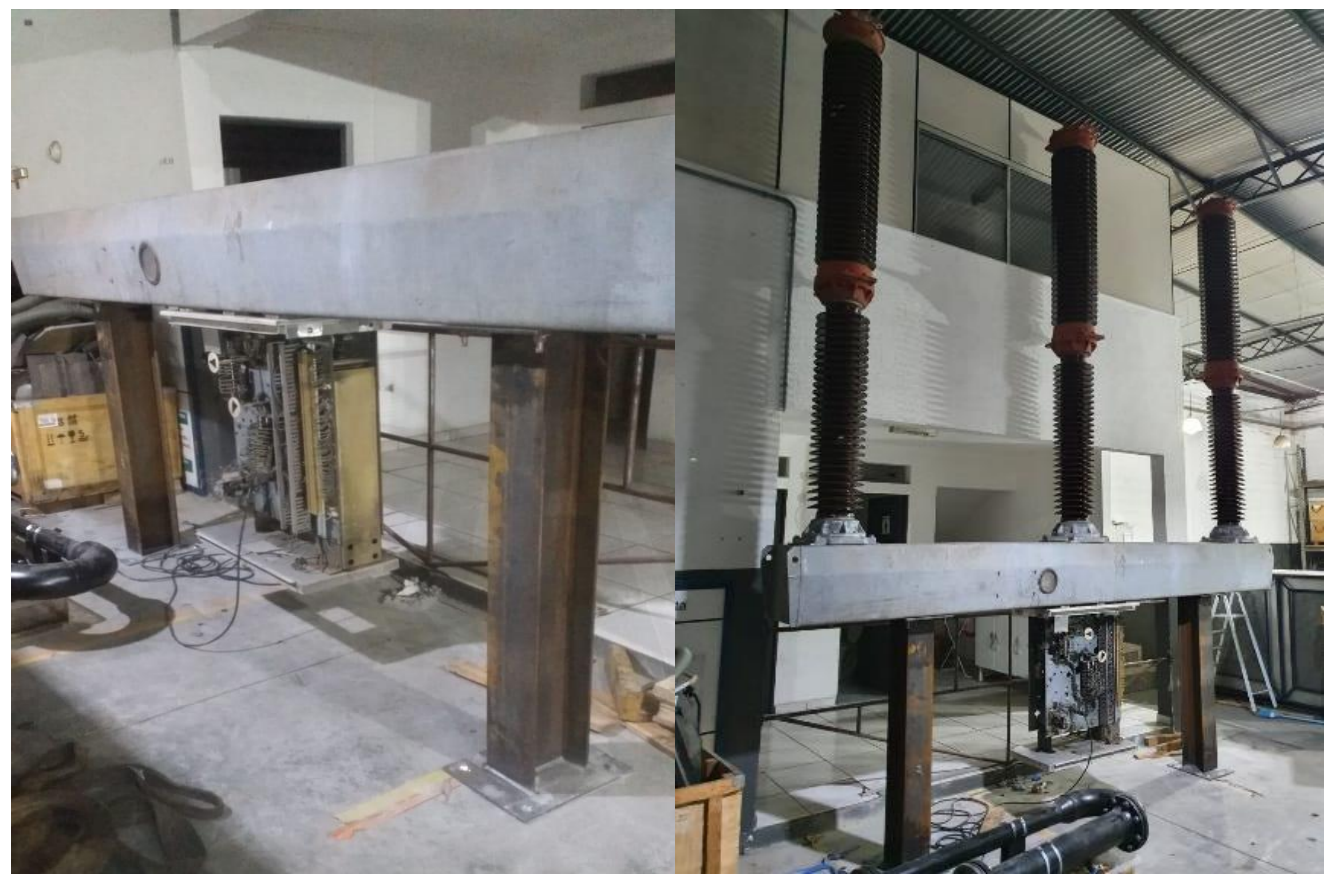

Figure 1. Details of the laboratory's construction.

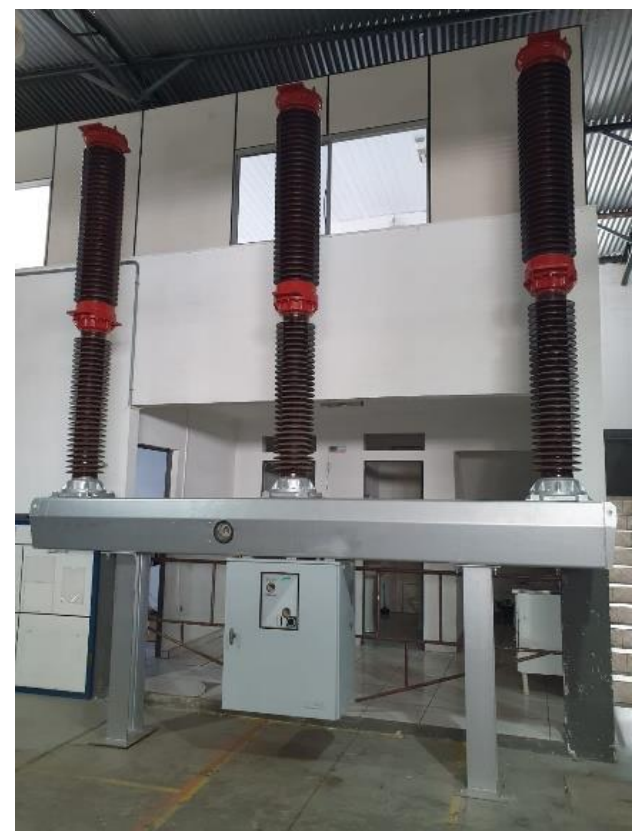

Figure 2. Circuit Breaker Testing Laboratory. 


\section{Passive Coupling Project}

This section deals with passive coupling between the signal injection prototype (which operates on a few volts) and a functioning lightning arrester (which can run from a few hundred volts to a few thousand volts). It shows that when the passive coupling is used, there is a compromise between the protection level for electronics and the resulting spectrum's functional area.

A more straightforward type of passive coupling would be a capacitor connected in series between the machine and the impedance analyzer. This proposition is one of the passive solutions pointed out in the online FRA in transformers [48]. However, to obtain a good attenuation of the high voltage signal, a low-value capacitor (which has a higher impedance, therefore) should be used. But as the impedance of this capacitor will decay only $20 \mathrm{db} / \mathrm{decade}$ with frequency, even at higher frequencies, this impedance may still be higher than the impedance of the generator, resulting in a "shadow" in the spectrum. Therefore, there will always be a compromise between the attenuation of high voltage in the fundamental frequency and the non-"shaded" functional region of the spectrum. Figure 3 shows the effect of coupling and its shadow on the range of impedances. The blue curve is the spectrum obtained without any coupling, while the curve in red represents the spectrum of this same winding with capacitive coupling. It is noted that the region of low frequencies (below fc) is completely "shaded," and the information contained in this region is lost. And due to the resonance series between $\mathrm{Lw}$ and $\mathrm{Cw}$, even a few frequencies above fc will also not present valuable information

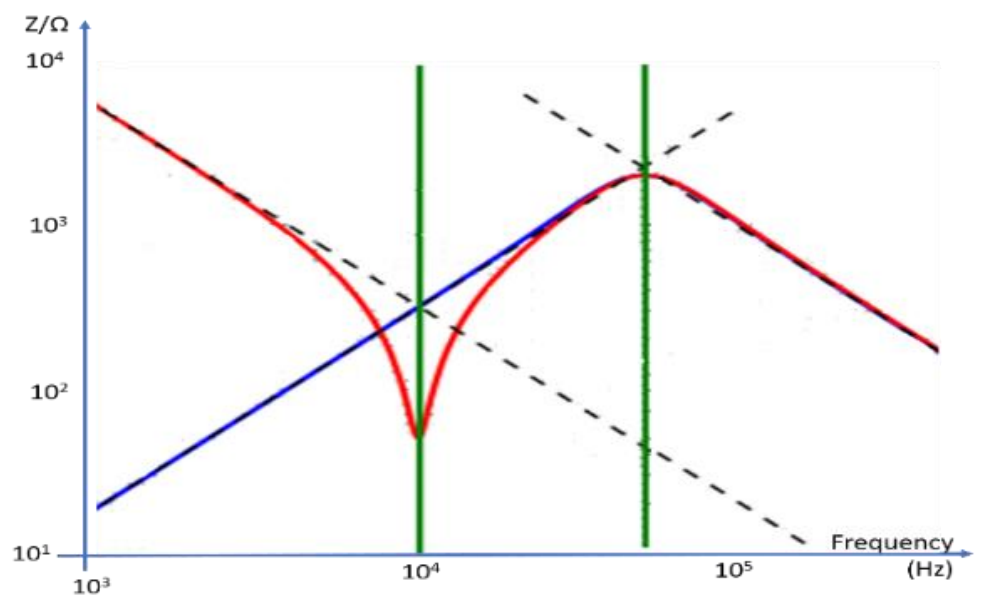

Figure 3. Effect of coupling on the spectrum of impedances.

\section{5/145 KV Curitiba Substation}

This section shows the initial ideas to the software of fault location in SF6 Curitiba substation. Figures 4 show the HIK-14 GIS (Isolated Gas Substation) substation. Figure 4 on the left shows the external view, and the model on the right exposes the internal view. It is possible to view the three buss that connects the substation equipment, highlighted in green, red, and yellow.

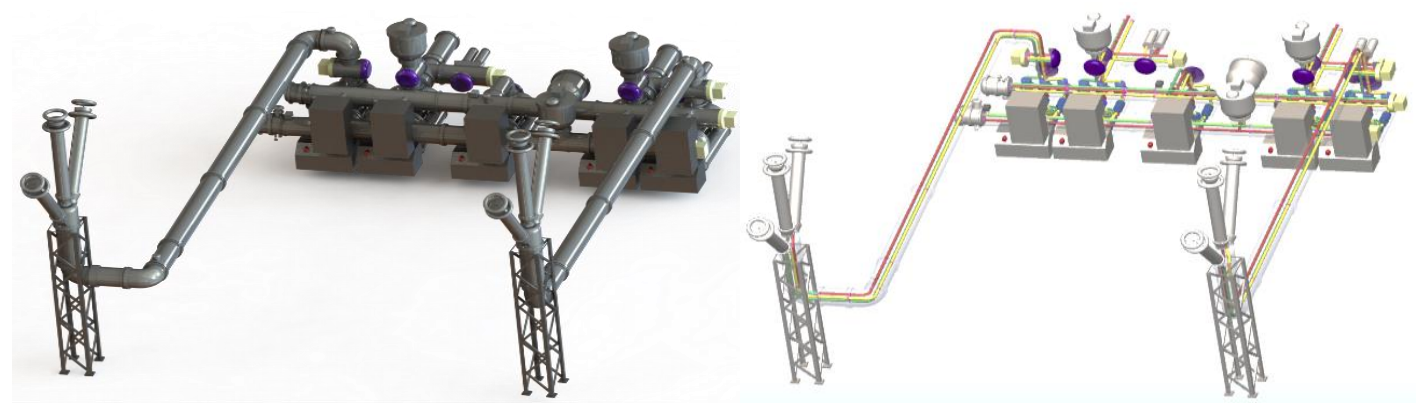

Figure 4. Substation GIS HLK-04 - External View (Left) and Inner View (Right).

Figures 5 show part of the substation isolated to SF6 and highlight the circuit breaker components: Breaker (1) and Operation Mechanism (2). The left figure shows the external view of the circuit breaker and the right to the inside. The right figure shows the three buss that make up the circuit breakers and the other substation components, highlighted in green, red, and yellow. 

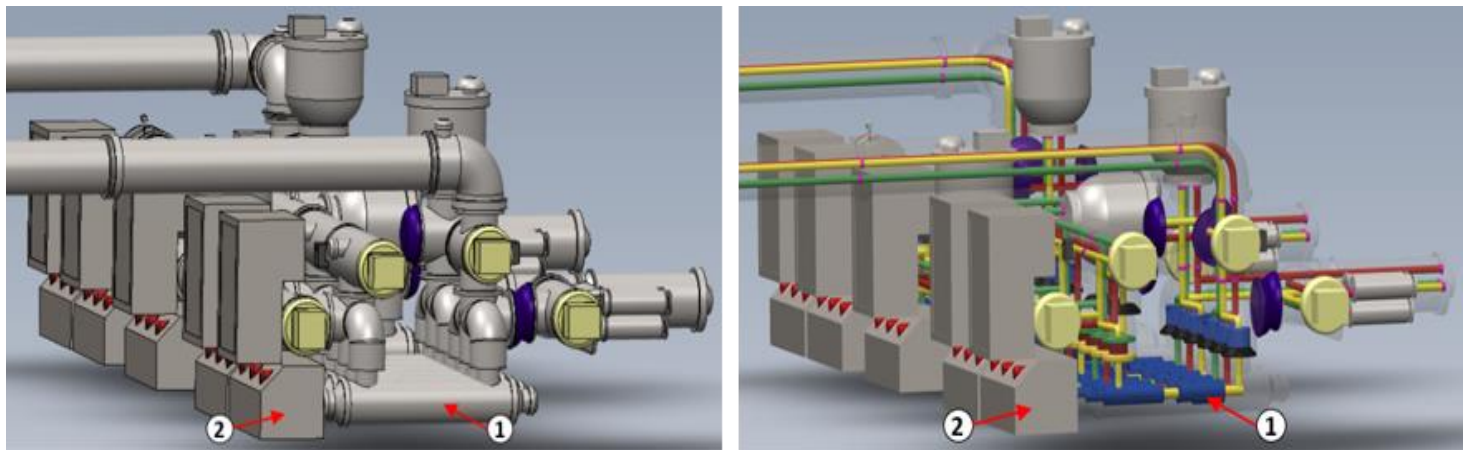

Figure 5. Circuit Breaker SF6 and Operation Mechanism - External View (Left) and Inner View (Right).

Figures 6 show part of the substation isolated to SF6 and highlight the disconnecting/grounding key components: Disconnecting/Grounding Key (1) and Operation Mechanism (2). The left figure shows the external view of the circuit breaker and the right to the inside. The right figure shows the three buss that connect the substation equipment, highlighted in green, red, and yellow.
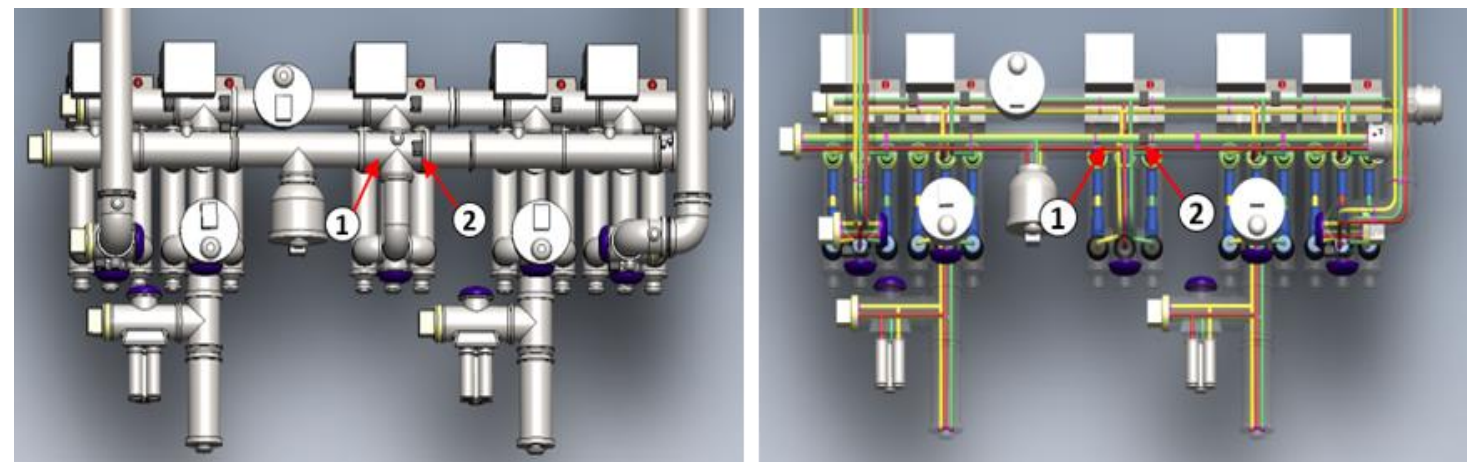

Figure 6. Disconnected/Grounding Key and Operation Mechanism - External (Left) and Inner (Right).

Figures 7 show the HLK-04Substation GIS (Gas Insulated Substation). The figure on the left shows the external view, and the model on the right exposes the internal view. You can see the three buss that connects the substation equipment, highlighted in green, red, and yellow.
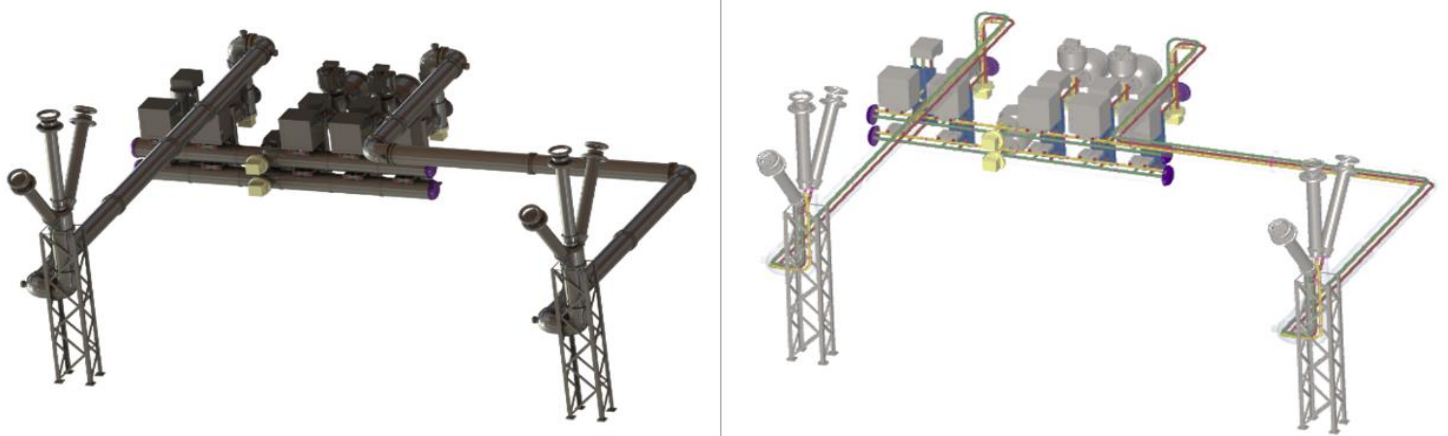

Figure 7. Substation GIS HLK-04 - External view (Left) and Inner View (Right).

Figures 8 show part of the substation isolated to SF6 and highlight the circuit breaker components: Breaker (1) and Operation Mechanism (2). The left figure shows the external view of the circuit breaker and the right to the inside. The right figure shows the three buss that make up the circuit breakers and the other substation components, highlighted in green, red, and yellow. 

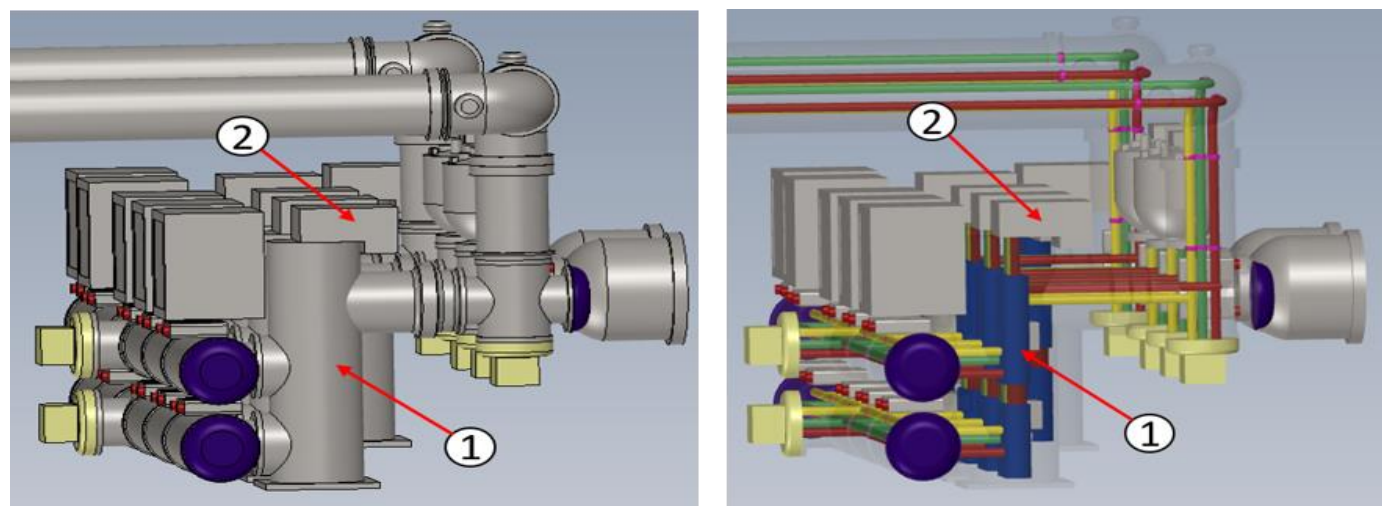

Figure 8. Circuit Breaker SF6 and Operation Mechanism - External View (Left) and Inner View (Right).

Figures 9 show part of the SF6 substation, highlighting the grounding key with short-circuit ability (1). The left figure shows the external view of the equipment and the internal connections on the right. The right figure shows the three buss that connect the substation equipment, highlighted in green, red, and yellow.
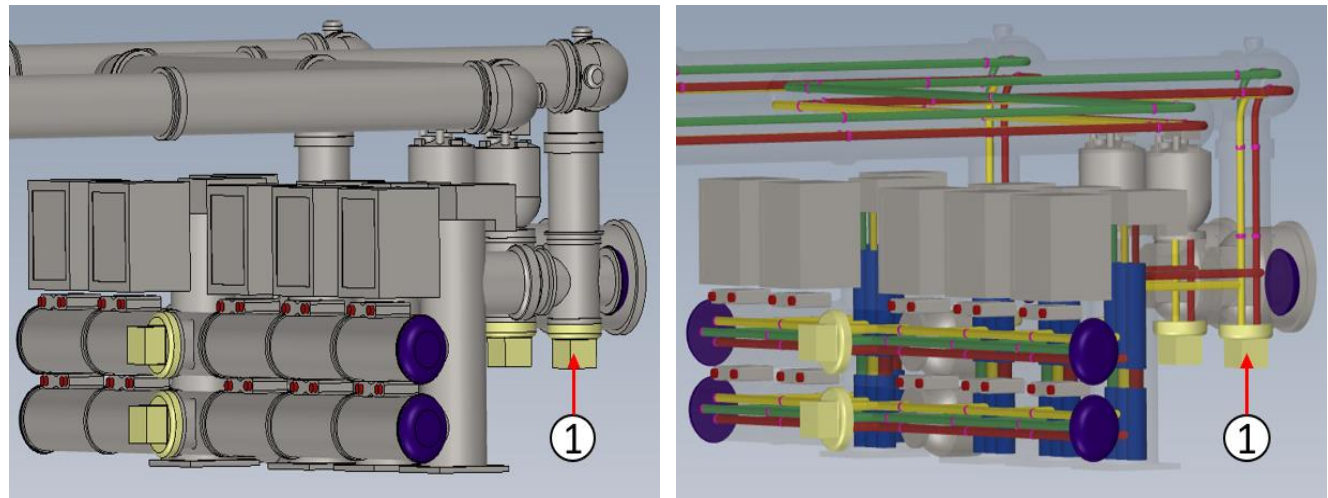

Figure 9. Grounding key with short circuit ability - External (Left) and internal view (Right).

\section{DISCUSSION}

This section presents the next steps of each project reported above, showing the currently developing activities. In the circuit breaker monitoring project, the next stage is Step 7, Design and Assembly of the Concept Prototype. The teams reconvene for the final preparation of the hardware of the prototype, still for POC. Then, in Step 8, Meeting of Data Analytics Results, the various interpretations of the sensors that were made will be unified together with the entry of historical, constructive, and operational data for the final assembly of the data analytics software.

Finally, in Step 9, Laboratory Tests of the Concept Prototype will take place. The tests will take place in the laboratory developed in Step 4 to verify the proposed methodology and conduct the Proof of Concept (POC), the central part of a project in the Applied Research phase.

In the lightning arresters monitoring project. Thus, in possession of the main definitions of the project, the development team is part of two: one linked to the Area of Insulation and Equipment and the other connected to the areas of Sensors and Communication, and Processing of Signals and Intelligent Systems. The first team performs or exhaustive tests in a high voltage laboratory in lightning arresters and their tablets to observe their degradation in the face of atmospheric discharges. In this stage, called Laboratory Testing in Lightning arresters and Their Tablets (Step 4), several lightning arresters will be tested and then opened to establish a cause-and-effect relationship. The physical consequences on your tablets can be verified. The other part of the team, formed by the areas of Sensors and Communication, and Signal Processing and Intelligent Systems, will focus on the Development of Sensors and Signal Injection Algorithms (Step 3) and on the Development of Sensors and Algorithms for Capturing and Interpreting Signals (Step 5). In step 3, the system power captor modules for the prototype's feeding and operation will be designed. The actuator modules will inject the signals in pre-programmed frequency and their operating algorithms. Also, at this stage will be developed the transducers' projects of energy capture and signal injection. In step 5, the multifrequency signal capture transducers and sensor modules will be designed with their analysis algorithms. 
Then, the teams rejoin for the Design and Assembly of the Prototype Concept (Step 6). The prototype that will test the concept will be designed, gathering information and developments from the previous steps. The prototype concept also has an incomplete configuration and consists only of the essential elements in the laboratory testing phase. Its construction must be done to allow hardware and software adjustments and modifications quickly. In the next step, Laboratory Tests of the Prototype Concept (Step 7), the tests will be developed to validate the proposed methodology. Tests will be made of the application and capture of the signals and the correct verification of the interpretations of the lightning arrester's operating conditions' degradation. With the results satisfied, the methodology is proven, and the phase of the Proof of Concept (POC) is finalized.

In the SF6 substation monitoring project, at this point in the project, the team is divided into two: one part is developing step 4 and the other, step5. In Step 4, the Computational Package, sensors, signal processing systems, and the communication system between the sensors and various other methods are being developed. The interpretation part of the signals will also be designed. In Step 5, Assembly of a Laboratory of Fault Location will happen the assembly of a virtual laboratory that can test the prototype in several situations, including when the protections do not act as expected.

\section{CONCLUSION}

This paper presents three on-going projects which have been developing, in the future, creating a joint base to increase the predictive maintenance inside of the COPEL Generation and Transmission. Three pieces of equipment are the main focus of these projects: circuit breakers, lightning arresters, and SF6 substation.

The circuit breaker monitoring project will establish a routine verification and monitoring of circuit breakers and their ability to interrupt throughout their service life. Possible deviations from established standards may generate alarms for checks by the maintenance team, in addition to monitoring wear and tear of internal elements to the circuit breaker.

Also, this project will contribute to a scientific and technological advance. Scientific, because as seen in the literature review, much is beginning to be discussed monitoring the circuit breakers in an on-line way, that is, with it in operation. And technological because it will have a continuous monitoring system of the operational conditions of its circuit breakers.

The lighting arrester monitoring project will contribute to a scientific and technological advance. Scientific, because seen in the literature review, discusses the behavior of lightning arresters in the face of atmospheric discharges. Still, most of them are interested in the lightning arrester as an environment of the electrical system and not as isolated equipment, that is, in its modeling and acting in the face of discharges, but not on the wear that occurs in it when it is hit by one of them. Studies are almost always systemic. In this project, one is not interested in modeling the lightning arresters but instead checking their wear and its inserts for various operative situations, affecting their operation. Thus, this project's focus is to establish the relationships between the energy dissipated when it goes through an atmospheric discharge and the deterioration of its tablets, making the prognosis of its useful life.

Technological advances are linked to the prototype to be developed. COPEL will leave in front of the other power utilities in the country having a device that can inform its technical staff of its lightning arresters' internal state and the need for a possible replacement before they are damaged, compromising the performance of the substation and the entire system.

A large substation's operation's interruption always generates undesirable consequences for the system, notified when this substation is part of an urban energy supply. Safety problems, risk of accidents, and material losses (both in homes and industries) can generate processes that go beyond possible fines or the lack of collection from the sale of energy. The image of the concessionaire is scratched with each shutdown. For all these reasons, these interruptions should occur for as long as possible. In this way, COPEL will leave in front of the other power utilities in the country having a system that can assist the operator in locating which compartment should be opened to be repaired in case of a fault. As already mentioned, this type of repair alone already generates problems. Still, its location is not evident, and the opening of a compartment is in place of the faulty compartment, generates costs, and increases the substation's downtime.

Thus, COPEL will be the pioneer and reference in the use of this type of system and may establish standards for standardization of the control of this type of operator aid system, and may in the future require that its substations already have more sensors and flags to increase the degree of observability of the arrangement.

Acknowledgments: The authors would like to express their thanks to CNPq, and CAPES. 
Funding: The projects presented in this paper are part of the R\&D projects: PD-06491-0509-2018, PD-06491-05112018, and PD-06491-0513-2018, executed by Gnarus Institute for COPEL Generation and Transmission, under the Brazilian Electric Sector Research and Development Program, regulated by the National Electric Energy Agency (ANEEL).

Conflicts of Interest: The authors declare no conflict of interest.

\section{REFERENCES}

1. Fordham Cooper W. Insulating oil to circuit-breaker failures. J Inst Elect Eng. - Part II: Power Eng. 1943 Feb;90(13):23-28. doi: 10.1049-ji-2.1943.0004.

2. Balsbaughm JC, Assaf AG. Electrical stability of electrical insulating oils under limited oxidation. Elect Eng. 1943 Jun;62(6):311-322. doi: 10.1109-EE.1943.6435778.

3. Leclerc JL, Smith MR, Jones GR. Pressure transients in a model gas-blast circuit breaker operating at extra high current levels. IEEE Trans Plasma Sc. 1980 Dec;8(4):376-384. doi: 10.1109-TPS.1980.4317343.

4. $\quad \operatorname{Sim}$ SH, Endrenyi J. Optimal preventive maintenance with repair. IEEE Trans Reliability. 1988 Apr;37(1):92-96. doi: 10.1109-24.3721.

5. Suzuki K, Ikeda H, Mizoguchi H, Ozaki Y, Yanabu S, Investigation of interruption performance of newly developed $300 \mathrm{kV}$ 3-phase-in-one-tank-type GCB and its application to a reduced size GIS. IEEE Trans Power Del. 1989 Jan;4(1):362-367. doi: 10.1109-61.19225.

6. Golubev A, Blokhintsev I, Paoletti G, Modrowski J. On-line partial discharge applications to MV electrical switchgear. Proceedings of the Electrical Insulation Conference and Electrical Manufacturing and Coil Winding Conference; 2001 Oct 16-18; Cincinnati, OH. Piscataway (NJ): IEEE; c2001. p. 225-32. doi: 10.1109EEIC.2001.965615.

7. Kawakita K, Ota H, Simokawa M, Kuwabara Y. Life management of GIS based on deterioration diagnosis of aged GIS. Proceedings of the IEEE-PES Transmission and Distribution Conference and Exhibition; 2002 Oct 6-10; Yokohama, Japan. Piscataway (NJ): IEEE; c2002. p. 802-6(2). doi: 10.1109-TDC.2002.1177578.

8. Suzuki A, et al. Deterioration diagnosis technique of housing rubber for composite hollow insulators. Proceedings of the 7th International Conference on Properties and Applications of Dielectric Materials; 2003 Jun 1-5; Nagoya, Japan. Piscataway (NJ): IEEE; c2003. p. 405-10(1). doi: 10.1109-ICPADM.2003.1218437.

9. Natti $S$, Jirutitijaroen $P$, Kezunovic M, Singh C. Circuit breaker and transformer inspection and maintenance: probabilistic models. Proceedings of the 2004 International Conference on Probabilistic Methods Applied to Power Systems; 2004 Sept 12-16; Ames, IA. Piscataway (NJ): IEEE; c2004. p. 1003-8.

10. Miki S, Okazawa H. Deterioration diagnosis of insulators for breakers using chemical evaluation and Mahalanobis-Taguchi (MT) method, Proceedings of the 2006 IEEE Conference on Electrical Insulation and Dielectric Phenomena; 2006 Oct 15-18; Kansas City, MO. Piscataway (NJ): IEEE; c2006. p. 473-6. doi: 10.1109/CEIDP.2006.311972.

11. Miki S, et al. Remaining Service Life Diagnostic Technology of Phenol Insulators for Circuit Breakers. IEEE Trans Dielectrics and Elect. Ins. 2008 Apr;15(2):476-83. doi: 10.1109-TDEI.2008.4483467.

12. Urayama M, et al. Evaluation of deterioration in aged GCBs and study on equipment replacement criteria. Proceedings of the 2009 Transmission e Distribution Conference e Exposition: Asia and Pacific; 2009 Oct 26-30; Seoul, South Korea. Piscataway (NJ): IEEE; c2009. p. 1-4. doi: 10.1109-TD-ASIA.2009.5357025.

13. Xin Z, et al. A high accurate sensor research and its application for VCBs internal pressure on-line condition monitor. Proceedings of the 2012 25th International Symposium on Discharges and Electrical Insulation in Vacuum (ISDEIV); 2012 Sept 2-7; Tomsk, Russia. Piscataway (NJ): IEEE; c2012. p.477-80. doi: 10.1109DEIV.2012.6412559.

14. Suwanasri T, Suwanasri C, Nobnorp S, Wattanawongpitak S. Performance evaluation based on symptom, failedtype and obsolescence criteria of high voltage circuit breaker, Proceedings of the 2013 10th International Conference on Electrical Engineering-Electronics, Computer, Telecommunications and Information Technology; 2013 May 15-17; Krabi, Thailand. Piscataway (NJ): IEEE; c2013. p.1-4. doi: 10.1109-ECTICon.2013.6559528.

15. Guan Y, Kezunovic M, Dehghanian P, Gurrala G. Assessing circuit breaker life cycle using condition-based data. Proceedings of the 2013 IEEE Power e Energy Society General Meeting; 2013 Jul 21-25; Vancouver, BC. Piscataway (NJ): IEEE; c2013. p.1-5. doi: 10.1109-PESMG.2013.6673062.

16. Pang Z, Ji H, Ma G, Li C, Cui X, Huang X. Linear particles behavior caused by circuit breaker action in GIS. Proceedings of the 2016 IEEE Conference on Electrical Insulation and Dielectric Phenomena (CEIDP); 2016 Oct 16-19; Toronto, ON. Piscataway (NJ): IEEE; c2016. p. 465-9. doi: 10.1109-CEIDP.2016.7785658.

17. Razi-Kazemi AA, Abdollah M. Novel high-frequency-based diagnostic approach for main contact assessment of high-voltage circuit breakers. IET Gen Tran Dist. 2018;12(5):1121-6. doi: 10.1049-iet-gtd.2017.0884. 
18. Dehghanian $\mathrm{P}$, Guan $\mathrm{Y}$, Kezunovic M. Real-time life-cycle assessment of circuit breakers for maintenance using on-line condition monitoring data. Proceedings of the 2018 IEEE-IAS 54th Industrial and Commercial Power Systems Technical Conference (leCPS); 2018 May 7-10; Niagara Falls, ON. Piscataway (NJ): IEEE; c2018. p.110. doi: 10.1109-ICPS.2018.8369996.

19. Grzybowski S, Gao G. Evaluation of $15-420 \mathrm{kV}$ substation lightning arresters after 25 years of service. Proceedings of the IEEE Southeastcon'99 - Technology on the Brink of 2000; 1999 Mar 25-28; Lexington, KY. Piscataway (NJ): IEEE; c2002. p.333-6. doi: 10.1109/SECON.1999.766151.

20. Garcia-Gracia M, Baldovinos S, Sanz M, Montanes L. Evaluation of the failure probability for gapless metal oxide arresters. Proceedings of the 1999 IEEE Transmission and Distribution Conference; 1999 Apr 11-16; New Orleans, LA. Piscataway (NJ): IEEE; c2002. p.700-5(2). doi: 10.1109/TDC.1999.756136.

21. Martinez MLB, Zanetta LC. On modeling and testing metal oxide resistors to evaluate the arrester withstanding energy. Proceedings of the 2000 Eighth International Conference on Dielectric Materials, Measurements and Applications; 2000 Sept 17-21; Edinburgh, UK. Piscataway (NJ): IEEE; c2002. p. 247-52. doi: 10.1049/cp:20000513.

22. Montanes L, Garcia-Gracia M, Sanz M, Garcia MA. An improvement for the selection of surge arresters based on the evaluation of the failure probability. IEEE Trans Power Del. 2002 Jan;17(1):123-8. doi: 10.1109/61.974198.

23. Lambert R, Tarasiewicz E, Xemard A, Fleury G. Probabilistic evaluation of lightning-related failure rate of power system apparatus. IEEE Trans Power Del. 2003 Apr;18(2):579-86. doi: 10.1109/TPWRD.2003.809732.

24. Christodoulou CA, Assimakopoulou FA, Gonos IG, Stathopulos IA. Simulation of metal oxide surge arresters behavior. Proceedings of the 2008 IEEE Power Electronics Specialists Conference; 2008 Jun 15-19; Rhodes, Greece. Piscataway (NJ): IEEE; c2008. p.1862-6. doi: 10.1109/PESC.2008.4592215.

25. Xingang C, Xiaoxiao T, Li F. Research of infrared diagnosed of faults of arrester. Proceedings of the 2008 International Conference on High Voltage Engineering and Application; 2008 Nov 9-12; Chongqing, China. Piscataway (NJ): IEEE; c 2009. p. 637-40. doi: 10.1109/ICHVE.2008.4774016.

26. Caulker D, Ahmad H, Abdul-Malek Z. Lightning Interaction with $132 \mathrm{kV}$ Transmission Line Protected by Surge Arresters. Proceedings of the 2011 46th International Universities' Power Engineering Conference; 2011 Sept 58; Soest, Germany. Piscataway (NJ): IEEE; c2012. pp. 1-5.

27. Jiang A, Fu Z, Sun W, Chen J, Wang G, Li R. Experimental and analytical studies of the effects of multiple lightning impulse currents on metal-oxide arrester blocks. Proceedings of the 2014 International Conference on Lightning Protection (ICLP); 2014 Oct 11-18; Shanghai, China. Piscataway (NJ): IEEE; c2014. p.681-7. doi: 10.1109/ICLP.2014.6973210.

28. Bassi W, Tatizawa $\mathrm{H}$. Early prediction of surge arrester failures by dielectric characterization. IEEE Elect Insulation Mag. 2016 Mar-Apr;32(2):35-42. doi: 10.1109/MEl.2016.7414229.

29. He J, Lin J, Liu W, Wang H, Liao Y, Li S. Structure-dominated failure of surge arresters by successive impulses. IEEE Trans Power Del. 2017 Aug;32(4):1907-14. doi: 10.1109/TPWRD.2016.2597191.

30. Tominaga S, Okutsu N, Mukae H, Takahashi Y, Matsuda S. Dynamic behavior of metal enclosures for gas insulated substations during ground faults and their immediate location by mechanical means. IEEE Trans Power App Syst. 1979 Jul;PAS-98(4):1283-90. doi: 10.1109/TPAS.1979.319441.

31. Perry MP. Fault location in gas insulated conductors using magnetic sensors. IEEE Trans Power App Syst. 1980 Jul;PAS-99(4):1543-7. doi: 10.1109/TPAS.1980.319579.

32. Chu FY, Tahiliani V. Gas-insulated substations fault survey. IEEE Trans Power App Syst. 1980 Nov;PAS99(6):2351-6. doi: 10.1109/TPAS.1980.319860.

33. Chu FY, Williamson A. Fault location in SF6 insulated substations using thermal techniques. IEEE Trans Power App Syst. 1982 Jul;PAS-101(7):1990-7. doi: 10.1109/TPAS.1982.317446

34. Boggs SA. Electromagnetic techniques for fault and partial discharge location in gas-insulated cables and substations. IEEE Trans Power App Syst. 1982 Jul;PAS-101(7):1935-41. doi: 10.1109/TPAS.1982.317482,

35. Memita N, Suzuki T, Itaka K, Furukawa H, Kikuchi K, Ninomiya K. Development and installation of 275KV SF6 gas-insulated transmission line. IEEE Trans Power App Syst. 1984 Apr;PAS-103(4):691-8. doi: 10.1109/TPAS.1984.318314.

36. Ushida K, Takagi I, Maruyama S, Sakakibara T, Kamata I. Arcing phenomena and their application for fault location in SF-6 insulated equipment. IEEE Trans Power Del. 1989 Jul;4(3):1751-6. doi: 10.1109/61.32669.

37. Lundgaard LE, Runde M, Skyberg B. Acoustic diagnosis of gas insulated substations: a theoretical and experimental basis. IEEE Trans Power Del. 1990 Oct;5(4):1751-9. doi: 10.1109/61.103670.

38. Jeyasurya B, Venkata SS, Vadari SV, Postforoosh J. Fault diagnosis using substation computer. IEEE Trans Power Del. 1990 Apr;5(2):1195-1201. doi: 10.1109/61.53141. 
39. Kezunovic M, Spasojevic P, Fromen CW, Sevcik DR. An expert system for transmission substation event analysis. IEEE Trans Power Del. 1993 Oct;8(4):1942-9. doi: 10.1109/61.248306.

40. Takagi I, et al. Application of gas pressure sensor for fault location system in gas insulated substation. IEEE Trans Power Del. 1995 Oct;10(4):1806-15. doi: 10.1109/61.473376.

41. Alves da Silva AP, Insfran AHF, da Silveira PM, Lambert-Torres G. Neural networks for fault location in substations. IEEE Trans Power Del. 1996 Jan;11(1):234-9. doi: 10.1109/61.484021.

42. Sakakibara T, Nakajima T, Maruyama S, Wakabayashi S, Nagaoka S. Development of GIS fault location system using pressure wave sensors. IEEE Trans Power Del. 1999 Apr;14(2):371-7. doi: 10.1109/61.754076.

43. Alves da Silva AP, Insfran AHF, Lambert-Torres G. Alarm processing based on associative neural memories with explanation capability. Int J Eng Intel Syst. 1999;7(2):109-15.

44. Lundgaard LE. Particles in GIS characterization from acoustic signatures. IEEE Trans Dielect Elect Insul. 2001 Dec;8(6):1064-74. doi: 10.1109/94.971466.

45. Okabe S, Kaneko S, Minagawa T, Nishida C. Detecting characteristics of SF6 decomposed gas sensor for insulation diagnosis on gas insulated switchgears. IEEE Trans Dielect Elect Insul. 2008 Feb;15(1):251-8. doi: 10.1109/T-DEI.2008.4446758.

46. Kezunovic M. Intelligent design. IEEE Power Energy Mag. 2010 Nov-Dec;8(6):37-44. doi: 10.1109/MPE.2010.938516.

47. Kezunovic M. Smart fault location for smart grids. IEEE Trans Smart Grid. 2011 Mar;2(1):11-22. doi: 10.1109/TSG.2011.2118774.

48. Santana WC, Salomon CP, Lambert-Torres G, Borges da Silva LE, Bonaldi EL, de Oliveira LEL, Borges da Silva JG. Early detection of insulation failures on electric generators through online frequency response analysis. Elect Power Syst Res. 2016 Nov;140:337-343. doi 10.1016/j.epsr.2016.06.007.

(C) (5) (5) 2021 by the authors. Submitted for possible open access publication under the terms and
conditions of the Creative Commons Attribution (CC BY NC) license
(https://creativecommons.org/licenses/by-nc/4.0/). 